\title{
Message of the President of the Brazilian League of Epilepsy
}

ia nove de setembro é o Dia Nacional de Epilepsia. Vários colegas trabalharam, neste início de setembro, em várias frentes na tentativa para combater a falta de informação, que, muitas vezes, gera preconceito e discriminação.

A Academia Brasileira de Neurologia $(\mathrm{ABN})$, através da Assessoria de Imprensa, preparou um documento para a imprensa e em parceria com a Liga Brasileira de Epilepsia (LBE), que representa o Departamento Científico de Epilepsia da ABN, indicou nomes de colegas da LBE de diversas cidades do Brasil para entrevistas em suas mídias locais.

A ASPE (Assistência à Saúde de Pacientes com Epilepsia), em parceria com a UNICAMP, Prefeitura de Campinas e APECAMP (Associação de Pessoas com Epilepsia de Campinas), realizaram a V Semana Nacional de Epilepsia, com várias atividades na cidade de Campinas com o intuito de conscientizar a sociedade para tirar a epilepsia das sombras.

A Associação Brasileira de Epilepsia (ABE), dentre outras atividades, organizou uma comemoração do dia Latino Americano de Epilepsia no dia 10 de setembro na Assembléia Legislativa da cidade de São Paulo, que incluiu um ciclo de palestras e vernissage do projeto Arte e Vida.

Manifestações como esta, reforçam o tema do Editorial deste número: "o crescente interesse dos autores mais jovens e colaboradores tradicionais por aspectos psicossociais, de qualidade de vida e comorbidades, relacionados à condição de viver com epilepsia".

Façamos votos que estas iniciativas se multipliquem e que com o esforço conjunto possamos em breve ver a Epilepsia fora das Sombras.

Fernando Cendes

Presidente 